\title{
Complete genome sequence of Peptoclostridium difficile strain Z31
}

\author{
Felipe L. Pereira', Carlos A. Oliveira Júnior², Rodrigo O. S. Silva², Fernanda A. Dorella', Alex F. Carvalho', \\ Gabriel M. F. Almeida', Carlos A. G. Leal ${ }^{1}$, Francisco C. F. Lobato ${ }^{2 \dagger}$ and Henrique C. P. Figueiredo ${ }^{1,3^{*}+}$
}

\begin{abstract}
Background: Peptoclostridium (Clostridium) difficile is a spore-forming bacterium responsible for nosocomial infections in humans. It is recognized as an important agent of diarrhea and colitis in several animal species and a possible zoonotic agent. Despite the known importance of $P$. difficile infection in humans and animals, no vaccine or other effective measure to control the disease is commercially available. A possible alternative treatment for $P$. difficile infection is the use of a nontoxigenic strain of $P$. difficile as a competitive exclusion agent. However, a thorough knowledge of this strain is necessary for this purpose. We selected P. difficile Z31, a nontoxigenic strain (PCR ribotype 009), for investigation because it prevents $P$. difficile infection in a hamster model.
\end{abstract}

Results: The genome sequence of P. difficile Z31 is a circular chromosome of 4298,263 bp, with a 29.21 \% GC content, encoding 4128 proteins, and containing 78 pseudogenes. This strain belongs to ST 3, clade 1, and has five phage regions in its genome. Genes responsible for resistance to tetracycline and erythromycin were detected and more importantly, Z31 also contains genes that promote spore production and stability, cell attachment, intestinal adherence, and biofilm formation.

Conclusion: In this study, we present the first complete genome sequence of nontoxigenic P. difficile strain Z31. When the Z31 genome was compared with those of other isolates available in GenBank, including a draft genome of a nontoxigenic strain, several unique regions were evident. Z31 contains no toxin genes, but encodes several nontoxin virulence factors, which may favor host colonization.

Keywords: Peptoclostridium (Clostridium) difficile, Live vaccine, Genome sequencing, Competitive exclusion

\section{Background}

Peptoclostridium difficile, initially called Bacillus difficilis, was first isolated from the meconium of newborns by Hall and O'Toole in 1935 [1]. The name 'Clostridium difficile' was made official in 1980 in the Approved Lists of Bacterial Names [2] based on a phenotypic study by Prevót [3]. Recently, in a study based on 16S rRNA and ribosomal protein sequences, Yutin and Galperin [4] proposed the reallocation of some Clostridium species into

\footnotetext{
*Correspondence: figueiredoh@yahoo.com

${ }^{\dagger}$ Francisco C. F. Lobato and Henrique C. P. Figueiredo contributed equally to this work

${ }^{3}$ Department of Preventive Veterinary Medicine, School of Veterinary, Federal University of Minas Gerais, Av. Antônio Carlos 6627, Pampulha, 30161-970 Belo Horizonte, MG, Brazil

Full list of author information is available at the end of the article
}

six new genera, renaming $C$. difficile 'Peptoclostridium difficile?

The genus Peptoclostridium, in the phylum Firmicutes, class Clostridia, order Clostridiales, and family Peptostreptococcaceae [4], is characterized by strictly anaerobic, motile, pleomorphic Gram-positive bacteria, with dimensions of $0.5-1.9 \times 3.0-16.9 \mu \mathrm{m}$, which form oval subterminal spores (Fig. 1) with a bacillus cell shape. The bacteria are spore-forming and mesophilic $\left(20-37{ }^{\circ} \mathrm{C}\right)$, with an optimal $\mathrm{pH}$ range of neutral to alkaline. They ferment fructose, glucose, levulose, mannitol, mannose, salicin, and usually xylose, but not galactose, glycerol, inulin, lactose, raffinose, or sucrose. They are chemoorganotrophs and can use yeast extract as their sole carbon and energy source and peptone as their nitrogen source. Peptoclostridium difficile liquefies gelatin, but does not attack 


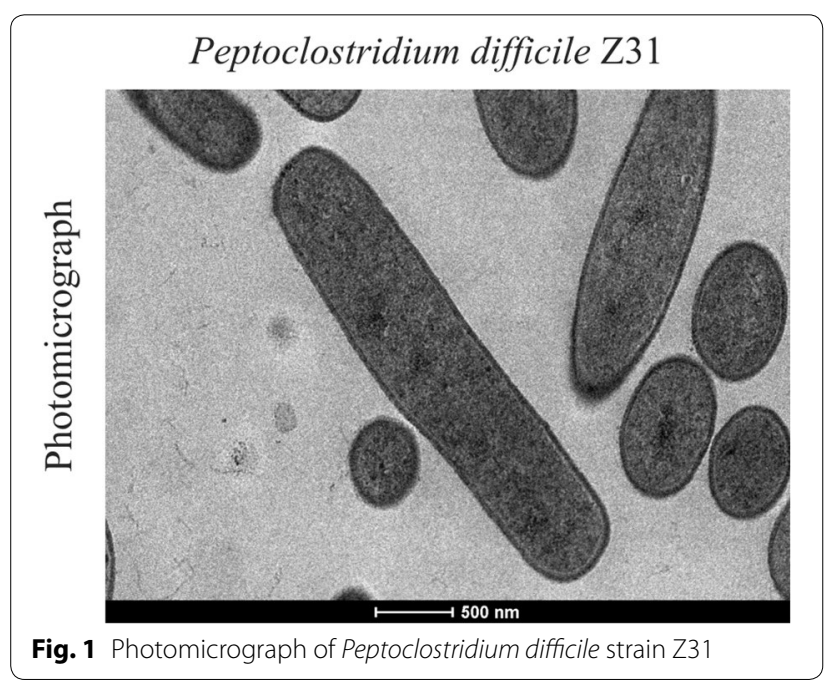

coagulated serum, milk, or meat proteins and is unable to reduce sulfate. It is negative for lecithinase, lipase, oxidase, and catalase. Acetate is produced as a major end product, but it also produces butyrate, formate, isobutyrate, isocaproate, isovalerate, lactate, and valerate [3-5].

Until the late 1970s, $P$. difficile was not recognized as pathogenic bacteria. However, in this decade, P. difficile and its toxins were related in fecal contents of human patients with pseudomembranous colitis [6] and the disease was reproduced in hamsters [7], confirming the importance of this microorganism as an enteropathogen. Today, this bacterium is known to be the cause of $P$. difficile infection (PDI), the main cause of nosocomial diarrhea in humans worldwide and a possible cause of diarrhea in general community $[8,9]$.

In veterinary medicine, $P$. difficile is the most important uncontrolled cause of neonatal diarrhea in piglets in the USA and Europe, and also occurs in other domestic animals and some wild species $[10,11]$. In piglets, CDI affects animals to 1-7 days of life, and it was demonstrated that until 1 day of life, $68-100 \%$ of the animals are infected by the microorganism [12, 13]. The disease is subclinical, and just few animals show diarrhea, however, the infection can affect the development of the animals causing economic losses to the farmer [14].

The pathogeny of PDI involves the colonization of colon by some toxigenic strain of $P$. difficile and production of its toxins, the toxin $\mathrm{A}$, an enterotoxin, and toxin $\mathrm{B}$, a cytotoxin, that act synergistically causing cytoskeleton damages, cell rounding, disruption of tight junctions and cell death [15]. The genes responsible to produce toxins, the main difference between toxigenic and nontoxigenic strains, are localized in a pathogenicity locus of $19 \mathrm{~kb}$, called PaLoc [16].

Despite the known importance of $P$. difficile in humans and animals, no vaccine is yet commercially available. Studies have shown that recombinant and classical immunogens expressing toxins $\mathrm{A}$ and $\mathrm{B}$ can prevent the occurrence of diarrhea or reduce the severity of $P$. difficile infection (PDI) in a rodent model [17]. These vaccines might limit, but cannot prevent, the fecal shedding of the microorganism, which is essential because $P$. difficile is a nosocomial pathogen. Because this bacterium is also a potential zoonotic agent, preventing its colonization of domestic animals should be a priority [10]. Among other alternative preventive strategies examined, the use of nontoxigenic $P$. difficile strains to prevent PDI has been shown to reduce the occurrence of the disease in humans and piglets by preventing their colonization by toxigenic strains [18-21].

There has been no report of the complete genome sequence of a nontoxigenic $P$. difficile strain, a necessary step in understanding this candidate live vaccine. Therefore, in this study, we determined the complete genome sequence of $P$. difficile nontoxigenic strain Z31.

\section{Methods}

\section{Growth conditions and DNA isolation}

Peptoclostridium difficile Z31, ribotype 009, a nontoxigenic strain isolated from a healthy dog on February 1, 2009, in the city of Belo Horizonte (state of Minas Gerais, Brazil), was selected for sequencing because it prevented PDI in hamster model [22], similar to some strains previously reported [23]. This strain was grown in Mueller-Hinton agar supplemented with $5 \%$ blood and $0.1 \%$ taurocholate at $37{ }^{\circ} \mathrm{C}$ under anaerobic conditions for 48-72 h. Its genomic DNA was extracted with the Maxwell $16^{\circledR}$ Research Instrument (Promega, USA) combined with lysozyme $(10 \mathrm{mg} / \mathrm{mL})$ and proteinase $\mathrm{K}$ $(20 \mathrm{mg} / \mathrm{mL})$. Briefly, cells were incubated overnight in lysozyme solution $(10 \mathrm{mg} / \mathrm{mL})$ at $37{ }^{\circ} \mathrm{C}$. Proteinase $\mathrm{K}$ was added and the mixture was incubated at $56{ }^{\circ} \mathrm{C}$ for $30 \mathrm{~min}$. According to the kit instructions: (i) the samples were lysed in the presence of a chaotropic agent and a detergent; (ii) the nucleic acids were bound to silica magnetic particles; (iii) the bound particles were washed, to isolate them from other cell components; and (iv) the nucleic acids were eluted into a formulation for sequencing. The extracted DNA was stored at $-80{ }^{\circ} \mathrm{C}$ until analysis.

\section{Genome sequencing and assembly}

The genome was sequenced with the Ion Torrent PGM ${ }^{\mathrm{TM}}$, in a mate-pair sequencing kit with an insert size of $3 \mathrm{kbp}$ ( 144-fold coverage) and with a fragment sequencing 400 bp kit ( 318-fold coverage). The quality of the raw data was analyzed with FastQC [24] and the sequence was assembled with the Mira 4.9.1 software [25] and Newbler 2.9 (Roche, USA) for the fragment library, and 
with SPAdes 3.5.0 [26] for the mate-pair library (the parameters for all the assembler software are shown in Additional file 1). This was the ab initio strategy applied to all libraries. The larges contigs obtained with Newbler and Mira were used as input, as trusted-contigs, in SPAdes. We obtained 20 scaffolds, with an N50 value of $698,574 \mathrm{bp}$, and the largest scaffold had a length size of 1691,449 bp. Gap filling was conducted with CLC Genomics Workbench 7 (Qiagen, USA), after the construction of a super scaffold with the CONTIGuator 2.0 software [27], using the default parameters and $P$. difficile strain CD196 (GenBank: NC_013315.1) as the reference. The gaps in the rRNA operon regions were filled by consensus mapping to the reference, and the remaining gaps were mapped recursively to the raw data on the gap flanks, and it was repeated several times until an overlap was found.

\section{Genome annotation}

The genome was annotated automatically with the Prokka 1.10 software (Rapid Bacterial Genome Annotation) [28], with the default parameters and nested databases in the order: TrEMBL Uniprot containing only (Pepto) Clostridium spp. proteins and RefSeq database. The genome was also curated manually in all putative frameshifts using the Artemis software [29], based on the coverage visualized with the CLC Genomics Workbench 7 software, with corrected indel assembly bias. Genes encoding signal peptides were identified with the SignalP 4.0 software [30] on a local installation, followed by the identification of transmembrane helices with Tmhmm 2.0 [31] and a Pfam domain search with PfamScan [32]. These three tools were used with their default parameters.

\section{Multilocus sequence typing (MLST) and in silico PCR}

MLST was performed with PubMLST (available at http:// pubmlst.org/cdifficile/) using the complete genome sequence. An in silico PCR search for genes related to virulence factors and antimicrobial resistance was performed with the jPCR software [33], with the default parameters and the primer sets shown in Additional file 2 .

\section{Quality assurance}

Genomic DNA was isolated from a pure bacterial isolate and confirmed with $16 \mathrm{~S}$ rRNA gene sequencing. All the raw sequencing data were mapped onto the final genome and the lack of contamination with other genomes was confirmed by the coverage and the low number of unmapped reads.

An alignment was constructed with the 16S rRNA sequence regions on the assembled scaffolds, predicted with the Barrnap software (available at https://github. com/tseemann/barrnap), and the $16 \mathrm{~S}$ rRNA genes of genomes available in GenBank. A phylogenetic tree was constructed from this alignment with the neighborjoining method based on 1000 randomly selected bootstrap replicates, using the CLC Genomic Workbench 7.0 software. On the tree, strain Z31 was positioned among other P. difficile strains (Fig. 2).

\section{Results and discussion}

After the genome assembly, gap filling, and annotation process, an in silico PCR was performed through searching for genes related to virulence factor, antibiotic resistance, and other known toxins. Considering the perspective of using the nontoxigenic strain Z31 to prevent PDI by competitive exclusion, some non-toxin virulence factors

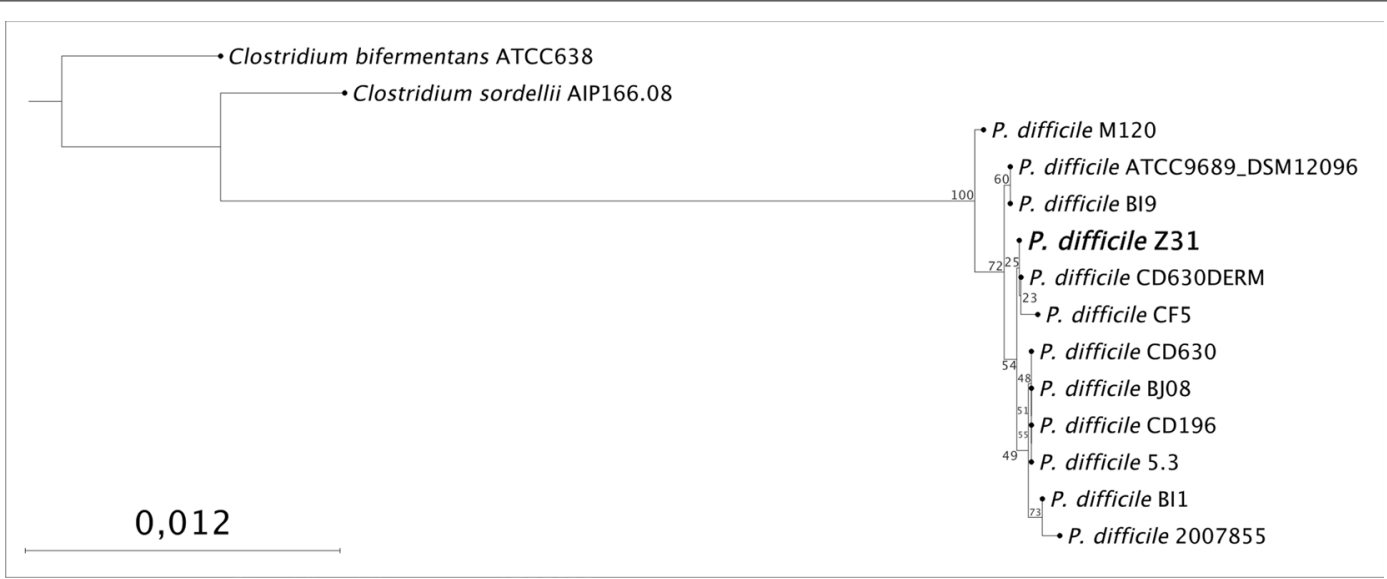

Fig. 2 Phylogenetic tree of Peptoclostridium difficile strain $\mathrm{Z31}$ representing the relative position in the genus Peptoclostridium based on $16 \mathrm{~S}$ sequences. The statistical method used was maximum likelihood and the bootstrap number was 1000. Thus, the values next to the nodes represent the percentage on the number of times, in 1000 repetitions, in which that clade was formed 
are desirable, predominantly those factors responsible for spore production and stability and those that promote cell attachment and host colonization. Z31 is positive for Cwp84 and surface-layer protein A (SlpA). SlpA is considered the major factor responsible for bacterial intestinal adherence, and Cwp84 is essential for the formation of that protein [34, 35]. GroEL, Cwp66, and a fibronectin-binding protein (Fbp68), which are also important in host-cell adherence, were also found [34-38]. Strain Z31 was also positive for genes encoding the flagellar proteins FliC and FliD, which play roles in the colonization and adherence of Z31 in vivo and are essential in later stages of biofilm formation [39-41]. These factors found in Z31 related to cell attachment are extremely important, because non toxigenic strains have to be able to compete with toxigenic strains by the colonization sites to prevent the disease [23].

The gene encoding the major regulator of sporulation in P. difficile, SpoOA, was detected in this strain. An absence or deficiency of Spo0A can cripple or impair the sporulation process [35, 42]. Genes encoding five spore coat proteins $(\cot A, \cot B, \cot C, \cot D$, and $\operatorname{sod} A)$ were also detected. The cotA protein is the most important protein in stabilizing the spore coat and ensures the integrity of this structure [43]. The formation of stable spores is also important for a nontoxigenic strain candidate to prevent the disease, because the bacteria need to pass through the stomach and be able to colonize the colon [23]. Vegetative cells are sensible to low $\mathrm{pH}$, on the other hand, the spores resist to this conditions, allowing a great number of viable particles reaches the colon [44]. Genes responsible for resistance to tetracycline (tetM) and erythromycin $(\mathrm{ermG})$ were also detected with previously described PCR primers [45, 46]. In contrast, none of the genes encoding proteins directly linked to toxin production were detected $(t c d A$, $t c d B, t c d C, c d t A$, or $c d t B$ ) [47] confirming the absence of the pathogenicity locus (PaLoc), which is essential for $P$. difficile infection [48].

Furthermore, the complete genomes of this species available at GenBank were selected to perform a similarity analysis with Gegenees software [49] with sequence fragmentation length of 500 nucleotides and a threshold of $30 \%$. Also, two complete genomes of species of the Clostridium genus were included as an outgroup. The similarity matrix was used to generate a heatplot and a ".nexus" format for phylogenomic analysis (Additional file 3). Although the Z31 strain is a nontoxigenic strain, the Additional file 3 shows that clade of this strain is paraphyletic with the type strain ATCC9689, a known as toxigenic strain, suggesting an evolutionary derivation of a same organism. Thereby, the nontoxigenic behavior of the Z31 strain seems to be occasioned by the losses of the toxin genes.

\section{Initial findings}

The $P$. difficile genome is composed of a circular chromosome of $4298,263 \mathrm{bp}$. The GC content is $29.21 \%$ and the genome contains 78 pseudogenes. Briefly, the genome has 4206 CDSs, and encodes 29 rRNAs, one transfermessenger RNA (tmRNA), and 58 tRNAs. Table 1 summarizes the subset of the 3809 genes with predicted functions that are associated with each COG functional categories. In summary, 3324 genes were predicted to have Pfam domains, 166 to have signal peptides, and 1011 to have transmembrane helices. No CRISPR repeats were found. Figure 3 shows the disposition of RNAs and CDSs coding sequences on the forward and reverse strands, the GC content, and the GC skew.

When the genome of Z31 was compared with those of other $P$. difficile strains deposited in GenBank [50], it showed high similarity to them

Table 1 Number of genes associated with general COG functional categories [55]

\begin{tabular}{|c|c|c|c|}
\hline Code & Value $^{\text {b }}$ & $\%$ age $^{a}$ & Description \\
\hline$J$ & 238 & 5.6585 & $\begin{array}{l}\text { Translation, ribosomal structure and biogen- } \\
\text { esis }\end{array}$ \\
\hline A & 0 & 0 & RNA processing and modification \\
\hline K & 479 & 11.3884 & Transcription \\
\hline$L$ & 184 & 4.3747 & Replication, recombination and repair \\
\hline$B$ & 1 & 0.0237 & Chromatin structure and dynamics \\
\hline $\mathrm{D}$ & 68 & 1.6167 & $\begin{array}{l}\text { Cell cycle control, cell division, chromosome } \\
\text { partitioning }\end{array}$ \\
\hline V & 134 & 3.1859 & Defense mechanisms \\
\hline $\mathrm{T}$ & 327 & 7.7746 & Signal transduction mechanisms \\
\hline M & 208 & 4.9453 & Cell wall/membrane biogenesis \\
\hline $\mathrm{N}$ & 79 & 1.8782 & Cell motility \\
\hline$U$ & 40 & 0.9510 & Intracellular trafficking and secretion \\
\hline $\mathrm{O}$ & 111 & 2.6390 & $\begin{array}{l}\text { Posttranslational modification, protein turno- } \\
\text { ver, chaperones }\end{array}$ \\
\hline C & 219 & 5.2068 & Energy production and conversion \\
\hline G & 310 & 7.3704 & Carbohydrate transport and metabolism \\
\hline$E$ & 321 & 7.6319 & Amino acid transport and metabolism \\
\hline $\mathrm{F}$ & 93 & 2.2111 & Nucleotide transport and metabolism \\
\hline $\mathrm{H}$ & 147 & 3.4950 & Coenzyme transport and metabolism \\
\hline I & 89 & 2.1160 & Lipid transport and metabolism \\
\hline$P$ & 168 & 3.9942 & Inorganic ion transport and metabolism \\
\hline Q & 57 & 1.3552 & $\begin{array}{l}\text { Secondary metabolites biosynthesis, transport } \\
\text { and catabolism }\end{array}$ \\
\hline $\mathrm{R}$ & 345 & 8.2025 & General function prediction only \\
\hline S & 251 & 5.9676 & Function unknown \\
\hline- & 2 & 0.0475 & Not in COGs \\
\hline \multicolumn{4}{|c|}{$\begin{array}{l}\text { The percentage is based on the total number of protein coding genes in the } \\
\text { annotated genome }\end{array}$} \\
\hline $\begin{array}{l}\mathrm{b} \text { The tc } \\
\text { because }\end{array}$ & otal not co & rrespond $\mathrm{t}$ & $\begin{array}{l}\text { o the final quantity of CDSs for each genome, } \\
\text { ociated with more than one COG functional }\end{array}$ \\
\hline
\end{tabular}




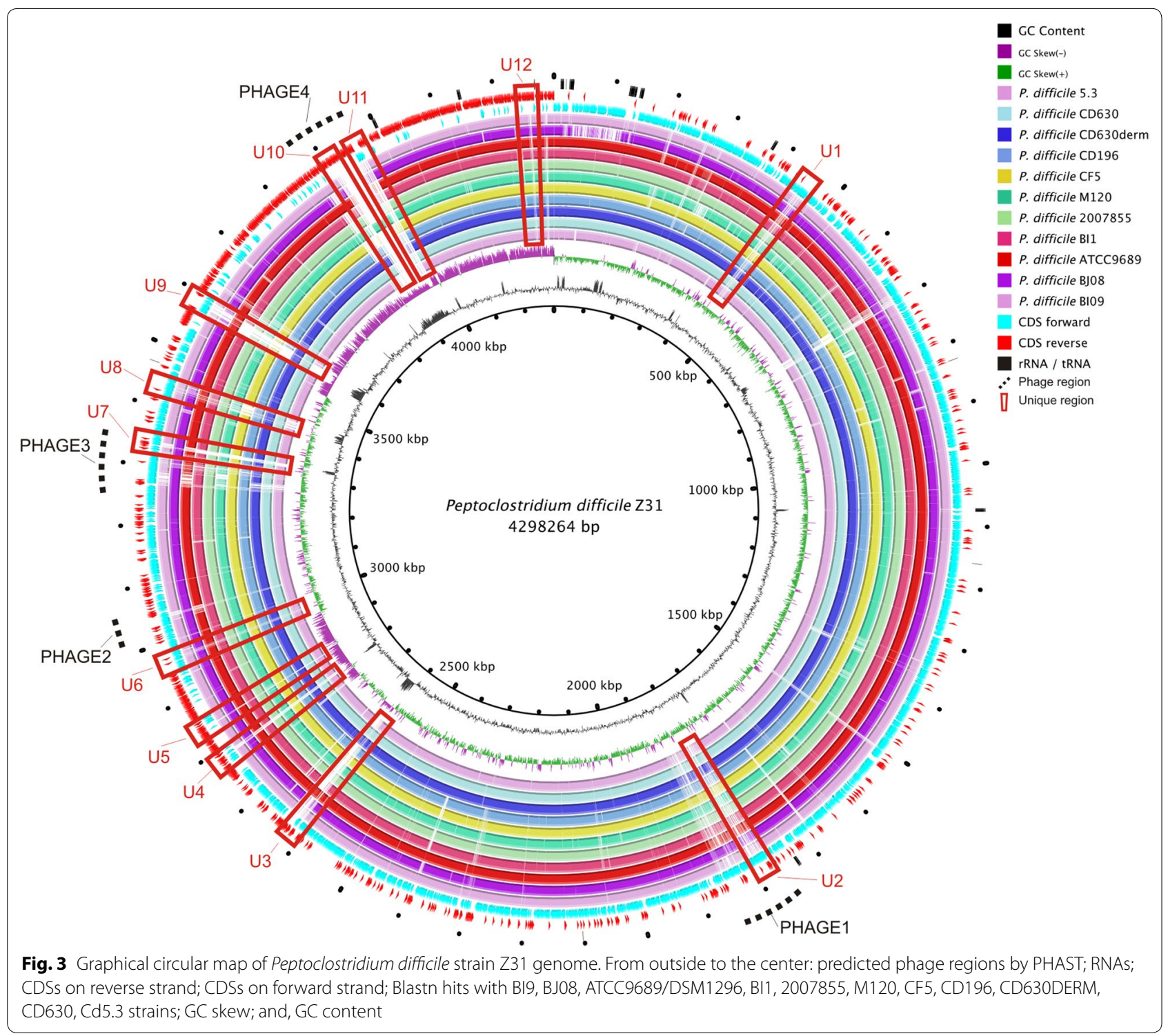

$(95.50 \pm 2.68 \%$-Additional file 3), with the exception of some genomic islands (Fig. 3), four of which were predicted with PHAST [51] to be phage regions. A brief description of these phages is given in Table 2.

A robust high-throughput MLST scheme for $P$. difficile was developed and validated [52], and allowed this species to be genotyped directly. Z31 was typed with MLST at loci $\operatorname{adk} 1, \operatorname{atp} A 1, d x r 2, \operatorname{gly} A 1, \operatorname{rec} A 1, \operatorname{sodA} 1$, and tpi 1, which classified this strain as ST3 in MLST clade 1. This result corroborates previous work, which reported that strains from PCR ribotype 009 are commonly classified as ST3 [53]. Strain Z31, P. difficile ATCC9689/ DSM1296, and P. difficile BI9 were the only three ST3 strains identified among the strains whose complete genomes or near-complete genomes (e.g., one scaffold) are deposited in GenBank. However, Z31 contain some unique regions, as shown in Fig. 3 (U1-U12). In contrast, P. difficile 5.3, described as nontoxigenic by Darling et al. [54], belongs to ST15, clade 1, a common classification for strains of PCR ribotype 010.

\section{Future directions}

Further analysis of the $P$. difficile Z31 genome will provide new information about the adaptation of this strain to the gastrointestinal tract, and new insights into its inhibition of toxigenic $P$. difficile strains. 
Table 2 Phage summary predicted by PHAST

\begin{tabular}{|c|c|c|c|c|c|}
\hline Number & Length (kbp) & Completeness & First common name & Keyword & GC content \\
\hline Phage 1 & 96.3 & Intact & Clostr_phi_CD119 & $\begin{array}{l}\text { Integrase, terminase, portal, head, capsid, tail, lysin, plate, and } \\
\text { protease }\end{array}$ & 28.9 \\
\hline Phage 2 & 24.1 & Incomplete & Clostr_phi_CD119 & Tail, lysin, and plate & 27.9 \\
\hline Phage 3 & 63.6 & Intact & Clostr_phiC2 & Integrase, terminase, portal, head, capsid, tail, and lysin & 28.6 \\
\hline Phage 4 & 138.1 & Intact & Bacill_G & $\begin{array}{l}\text { Protease, recombinase, tail, transposase, integrase, head, capsid, } \\
\text { portal, and terminase }\end{array}$ & 35.7 \\
\hline
\end{tabular}

\section{Availability of supporting data}

This whole-genome shotgun sequence has been deposited in the DDBJ/EMBL/GenBank databases under accession number CP013196. The version described in this paper is the first version CP013196.1.

\section{Additional files}

Additional file 1. Assembler software (Mira, Newbler and SPAdes) parameters.

Additional file 2. Primer sets used on in silico PCR for genes related to virulence factor, antibiotic resistance, and other known toxins.

Additional file 3. Phylogenomic analysis performed using Gegenees.

\section{Abbreviations}

GC content: number of $G$ and $C$ nucleotides; rRNA: ribosomal RNA; PDI: Peptoclostridium difficile infection; PGM: Personal Genome Machine; tmRNA: transport-messenger RNA; tRNA: transport RNA; MLST: multilocus sequence typing.

\section{Authors' contributions}

FLP, HCPF, FAD, ROSS, and CAOJ drafted the manuscript. FAD, AFC, and GMFA performed the laboratory experiments. FLP, FAD, and AFC sequenced, assembled, and annotated the genome. FLP performed the bioinformatics analyses. HCPF and FCFL designed and coordinated all the experiments. All authors have read and approved the final manuscript.

\section{Author details \\ ${ }^{1}$ National Reference Laboratory for Aquatic Animal Diseases (AQUACEN), Ministry of Fisheries and Aquaculture, Federal University of Minas Gerais, Belo Horizonte, Brazil. ${ }^{2}$ Veterinary School, Federal University of Minas Gerais, Belo Horizonte, Brazil. ${ }^{3}$ Department of Preventive Veterinary Medicine, School of Veterinary, Federal University of Minas Gerais, Av. Antônio Carlos 6627, Pampulha, 30161-970 Belo Horizonte, MG, Brazil.}

\section{Acknowledgements}

This work was supported by Conselho Nacional de Desenvolvimento Científico e Tecnológico (CNPq), Ministério da Pesca e Aquicultura and Fundação de Amparo à Pesquisa do Estado de Minas Gerais (FAPEMIG). We also acknowledge support from the Coordenação de Aperfeiçoamento de Pessoal de Nível Superior (CAPES).

\section{Competing interests}

The authors declare that they have no competing interests.

Received: 20 November 2015 Accepted: 3 March 2016 Published online: 01 April 2016

\section{References}

1. Hall IC, O'toole E. Intestinal flora in newborn infants with a description of a new pathogenic anaerobe, Bacillus difficilis. Am J Dis Child. 1935. doi:10.1001/archpedi.1935.01970020105010.

2. Skerman VBD, Mcgowan V, Sneath PHA. Approved Lists of Bacterial Names. Int J Syst Bacteriol. 1980;30:225-420.

3. Prévot AR. Études de systématique bactérienne IV. Critique de la conception actuelle du genre Clostridium. In: Cato EP, Hash DE, Holdeman LV et al, editors. Electrophoretic study of Clostridium species. J Clin Microbiol. 1982;15:668-702.

4. Yutin N, Galperin MY. A genomic update on clostridial phylogeny: Gramnegative spore formers and other misplaced clostridia. Environ Microbiol. 2013. doi:10.1111/1462-2920.12173.

5. Hatheway CL. Toxigenic Clostridia. Clin Microbiol Rev. 1990;3(1):66-98.

6. George RH, Symonds JM, Dimock F, Brown JD, Arabi Y, Shinagawa N, Keighley MR, Alexander-Williams J, Burdon DW. Identification of Clostridium difficile as a cause of pseudomembranous colitis. Br Med J. 1978;1:695.

7. Larson HE, Price AB, Honour P, Borrielo SP. Clostridium difficile and the aetiology of pseudomembranous colitis. Lancet. 1978;1:1063-6.

8. Khan FY, Elzouki AN. Clostridium difficile infection: a review of the literature. Asian Pac J Trop Med. 2014. doi:10.1016/S1995-7645(14)60197-8.

9. Ogielska M, Lanotte P, Le Brun C, Valentin AS, Garot D, Tellier AC, Halimi JM, Colombat P, Guilleminault L, Lioger B, Vegas H, De Toffol B, Constans T, Bernard L. Emergence of community-acquired Clostridium difficile infection: the experience of a French hospital and review of the literature. Int J Infect Dis. 2015. doi:10.1016/j.ijid.2015.06.007.

10. Songer JG. Clostridia as agents of zoonotic disease. Vet Microbiol. 2010. doi:10.1016/j.vetmic.2009.07.003.

11. Silva RO, D'Elia ML, Teixeira ÉP, Pereira PL, de Magalhaes Soares DF, Cavalcanti ÁR, Kocuvan A, Rupnik M, Santos AL, Junior CA, Lobato FC. Clostridium difficile and Clostridium perfringens from wild carnivore species in Brazil. Anaerobe. 2014;31(28):207-11.

12. Hopman NE, Keessen EC, Harmanus C, Sanders IM, van Leengoed LA, Kuijper EJ, Lipman LJ. Acquisition of Clostridium difficile by piglets. Vet Microbiol. 2011. doi:10.1016/j.vetmic.2010.10.013.

13. Schneeberg A, Neubauer H, Schmoock G, Baier S, Harlizius J, Nienhoff $H$, Brase K, Zimmermann S, Seyboldt C. Clostridium difficile genotypes in piglet population in Germany. J Clin Microbiol. 2013. doi:10.1128/ JCM.01440-13.

14. Songer JG, Anderson MA. Clostridium difficile: an important pathogen of food animals. Anaerobe. 2006;12(1):1-4.

15. Carter GP, Rood JI, Lyras D. The role of toxin A and toxin B in Clostridium difficile-associated disease. Gut Microbes. 2010. doi:10.4161/ gmic.1.1.10768.

16. Voth DE, Ballard JD. Clostridium difficile toxins: mechanism of action and role in disease. Clin Microbiol Rev. 2005. doi:10.1128/ CMR.18.2.247-263.2005.

17. Leuzzi R, Adamo R, Scarselli M. Vaccines against Clostridium difficile. Hum Vaccines Immunother. 2014. doi:10.4161/hv.28428.

18. Songer JG, Jones R, Anderson MA, Barbara AJ, Post KW, Trinha HT. Prevention of porcine Clostridium difficile-associated disease by competitive 
exclusion with nontoxigenic organisms. Vet Microbiol. 2007. doi:10.1016/j. vetmic.2007.04.019.

19. Merrigan MM, Sambol SP, Johnson S, Gerding DN. New approach to the management of Clostridium difficile infection: colonisation with nontoxigenic C. difficile during daily ampicillin or ceftriaxone administration. Int J Antimicrob Agents. 2009. doi:10.1016/S0924-8579(09)70017-2.

20. Villano SA, Seiberling M, Tatarowicz W, Monnot-Chase E, Gerding DN. Evaluation of an oral suspension of VP20621, spores of nontoxigenic Clostridium difficile strain M3, in healthy subjects. Antimicrob Agents Chemother. 2012. doi:10.1128/AAC.00913-12.

21. Nagaro KJ, Phillips ST, Cheknis AK, Sambol SP, Zukowski WE, Johnson S, Gerdinga DN. Nontoxigenic Clostridium difficile protects hamsters against challenge with historic and epidemic strains of toxigenic BI/NAP1/027 C. difficile. Antimicrob Agents Chemother. 2013. doi:10.1128/AAC.00580-13.

22. Oliveira CA, Silva ROS, Diniz NA, Pires PS, Lobato FCF, Assis RA. Prevention of Clostridium difficile infection in hamsters using a non-toxigenic strain. Cienc Rural. 2016. doi:10.1590/0103-8478cr20150454.

23. Sambol SP, Merrigan MM, Tang JK, Johnson S, Gerding DN. Colonization for the prevention of Clostridium difficile disease in Hamsters. J Infect Dis. 2002. doi:10.1086/345676

24. FastQC. Babraham Bioinformatics. http://www.bioinformatics.babraham ac.uk/projects/fastqc. 2015. Accessed 07 Sept 2015.

25. Chevreux B, Wetter T, Suhai S. Genome sequence assembly using trace signals and additional sequence information. Comput Sci Biol Proc Ger Conf Bioinform. 1999;99:45-56.

26. Nurk S, Bankevich A, Antipov D, et al. Assembling genomes and mini-metagenomes from highly chimeric reads. Res Comput Mol Biol. 2013;7821:158-70.

27. Galardini M, Biondi EG, Bazzicalupo M, Mengoni A. CONTIGuator: a bacterial genomes finishing tool for structural insights on draft genomes. Source Code Biol Med. 2011. doi:10.1186/1751-0473-6-11.

28. Seemann T. Prokka: rapid prokaryotic genome annotation. Bioinformatics. 2014. doi:10.1093/bioinformatics/btu153.

29. Rutherford K, Parkhill J, Crook J, et al. Artemis: sequence visualization and annotation. Bioinformatics. 2000;16:944-5.

30. Petersen TN, Brunak S, von Heijne G, Nielsen H. SignalP 4.0: discriminating signal peptides from transmembrane regions. Nat Methods. 2011. doi:10.1038/nmeth.1701.

31. Sonnhammer EL, von Heijne G, Krogh A. A hidden Markov model for predicting transmembrane helices in protein sequences. Proc Int Conf Intell Syst Mol Biol. 1998;6:175-82.

32. Mistry J, Bateman A, Finn RD. Predicting active site residue annotations in the Pfam database. BMC Bioinform. 2007. doi:10.1186/1471-2105-8-298.

33. Kalendar R, Lee $D$, Schulman $A H$. Java web tools for $P C R$, in silico $P C R$, and oligonucleotide assembly and analysis. Genomics. 2011. doi:10.1016/j. ygeno.2011.04.009.

34. Merrigan MM, Venugopal A, Roxas JL, Anwar F, Mallozzi MJ, Roxas BAP, et al. Surface-layer protein A (SIpA) is a major contributor to host-cell adherence of Clostridium difficile. PLoS One. 2013. doi:10.1371/journal. pone.0078404.

35. Awad MM, Johanesen PA, Carter GP, Rose E, Lyras D. Clostridium difficile virulence factors: insights into an anaerobic spore-forming pathogen. Gut Microbes. 2014. doi:10.4161/19490976.2014.969632.

36. Hennequin C, Porcheray F, Waligora-Dupriet A, Collignon A, Barc M, Bourlioux P, Karjalainen T. GroEL (Hsp60) of Clostridium difficile is involved in cell adherence. Microbiology. 2001;147(Pt 1):87-96.

37. Waligora A, Hennequin C, Mullany P, Bourlioux P, Collignon A, Karjalainen T. Characterization of a cell surface protein of Clostridium difficile with adhesive properties. Infect Immun. 2001. doi:10.1128/ |Al.69.4.2144-2153.2001.

38. Lin Y, Kuo C, Koleci X, McDonough SP, Chang Y. Manganese binds to Clostridium difficile Fbp68 and is essential for fibronectin binding. J Biol Chem. 2011. doi:10.1074/jbc.M110.184523.
39. Baban ST, Kuehne SA, Barketi-Klai A, Cartman ST, Kelly ML, Hardie KR, Kansau I, Collignon A, Minton NP. The role of flagella in Clostridium difficile pathogenesis: comparison between a non-epidemic and an epidemic strain. PLoS One. 2013. doi:10.1371/journal.pone.0073026.

40. Đapa T, Leuzzi R, Ng YK, Baban ST, Adamo R, Kuehna SA, Scarselli M, Minton NP, Serruto D, Unnikrishnan M. Multiple factors modulate biofilm formation by the anaerobic pathogen Clostridium difficile. J Bacteriol. 2013. doi:10.1128/JB.01980-12.

41. Dingle TC, Mulvey GL, Armstrong GD. Mutagenic analysis of the Clostridium difficile flagellar proteins, FliC and FliD, and their contribution to virulence in hamsters. Infect Immun. 2011. doi:10.1128/IAI.05305-11.

42. Mackin KE, Carter G, Howarth P, Rood Jl, Lyras D. Spo0A differentially regulates toxin production in evolutionarily diverse strains of Clostridium difficile. PLoS One. 2013. doi:10.1371/journal.pone.0079666.

43. Permpoonpattana P, Phetcharaburanin J, Mikelsone A, Dembek M, Tan S, Brisson MC, Ragione R, Brisson AR, Fairweather N, Hong HA, Cutting SM. Functional characterization of Clostridium difficile spore coat proteins. J Bacteriol. 2013. doi:10.1128/JB.02104-12.

44. Jump RLP, Pultz MJ, Donskey CJ. Vegetative Clostridium difficile survives in room air on moist surfaces and in gastric contents with reduced acidity: a potential mechanism to explain the association between proton pump inhibitors ans C. difficile-associated diarrhea? Antimicrob Agents Chemother. 2007. doi:10.1128/AAC.01443-06.

45. Patterson AJ, Colangeli R, Spigaglia P, Scott KP. Distribution of specific tetracycline and erythromycin resistance genes in environmental samples assessed by macroarray detection. Environ Microbiol. 2007. doi:10.1111/j.1462-2920.2006.01190.x.

46. Spigaglia P, Barbanti F, Mastrantonio P. Detection of a genetic linkage between genes coding for resistance to tetracycline and erythromycin in Clostridium difficile. Microb Drug Resist. 2007. doi:10.1089/mdr.2007.723.

47. Persson S, Torpdahl M, Olsen KEP. New multiplex PCR method for the detection of Clostridium difficile toxin $A(\operatorname{tcd} A)$ and toxin $B(\operatorname{tcd} B)$ and the binary toxin (cdtA/cdtB) genes applied to a Danish strain collection. Clin Microbiol Infect. 2008. doi:10.1111/j.1469-0691.2008.02092.x.

48. Dingle KE, Elliot B, Robinson E, Griffiths D, Eyre DW, Stoesser N, Vaughan A, Golubchik T, Fawley WN, Wilcox MH, Peto TE, Walker AS, Riley TV, Crook DW, Didelot X. Evolutionary history of the Clostridium difficile pathogenicity locus. Genome Biol Evol. 2014. doi:10.1093/gbe/evt204.

49. Agren J, Sundström A, Håfström T, Segerman B. Gegenees: fragmented alignment of multiple genomes for determining phylogenomic distances and genetic signatures unique for specified target groups. PLoS One. 2012;7:e39107.

50. GenBank. NCBI, USA. 2015. http://www.ncbi.nlm.nih.gov/genbank. Accessed 22 Sept 2015.

51. Zhou Y, Liang Y, Lynch KH, Dennis JJ, Wishart DS. PHAST: a fast phage search tool. Nucl Acids Res. 2011. doi:10.1093/nar/gkr485.

52. Griffiths D, Fawley W, Kachrimanidou M, Bowden R, Crook DW, Fung R, et al. Multilocus sequence typing of Clostridium difficile. J Clin Microbiol. 2010. doi:10.1128/JCM.01796-09.

53. Kurka H, Ehrenreich A, Ludwig W, Monot M, Rupnik M, Barbut F, Indra A, Dupuy B, Liebl W. Sequence similarity of Clostridium difficile strains by analysis of conserved genes and genome content is reflected by their ribotype affiliation. PLoS One. 2014. doi:10.1371/journal.pone.0086535.

54. Darling AE, Worden P, Chapman TA, Chowdhury PR, Charles IG, Djordjevic SP. The genome of Clostridium difficile 5.3. Gut Pathogens. 2014. doi:10.1186/1757-4749-6-4.

55. Galperin MY, Makarova KS, Wolf Yl, Koonin EVA. Expanded microbial genome coverage and improved protein family annotation in the COG database. Nucl Acids Res. 2015. doi:10.1093/nar/gku1223. 